\title{
NIETZSCHE Y LA ANTIGÜEDAD: LA CRÍTICA A LA OBJETIVIDAD CIENTÍFICA COMO VERDAD TEOLÓGICA
}

Nietzsche and the Ancient Time:

Criticizing the Conception of Scientific Objectivity as Theological Truth

\author{
Mónica Salcido Macías \\ UNAM, México
}

\begin{abstract}
RESUMEN: El presente artículo reflexiona sobre el modo en que Nietzsche, en su reinterpretación del mundo griego y en el margen de una visión de la historia al servicio de la vida, postula un perspectivismo que lucha contra el sueño objetivista de la ciencia histórica decimonónica de contar «cómo realmente sucedieron los hechos». Se postula que la crítica nietzscheana a la filología clásica supone el cuestionamiento de los fines racionalistas de la verdad científica como tendencia moral a la verdad y expresión de una teleología de corte cristiano, para optar por un nuevo acercamiento histórico, al que Sloterdijk y White llaman «mitológico».
\end{abstract}

Palabras clave: objetividad - cristianismo - mito - ciencia - Antigüedad

ABSTRACT: This article deals with the way in which Nietzsche, in his reinterpretation of the Greek World and on the margins of a vision of history at the service of life, postulates a Perspectivism against nineteenth-century historical science's objectivistic dream of narrating «how the facts really happened». The article holds that the Nietzschean critique of Classical Philology involves questioning the rationalistic goals of scientific truth as a moral tendency towards truth and an expression of a Christian biased teleology, in order to uphold a new historical approach, an approach termed as «mythological» by Sloterdijk and White.

Keywords: Objectivity - Christianity - Myth - Science - Antiquity

\section{LA DRAMATURGIA DE LA HISTORIA}

La historia, como parte esencial de las "ciencias del espíritu», como expresión del deseo de salvar el pasado del olvido, no escapa a la finitud y la transitoriedad de aquel que la produce: el ser humano. Pese a fundamentarse en la necesidad de Verdad, de decir "cómo realmente sucedieron los hechos», el sueño de objetividad de la historia considerada como ciencia se esfuma ante la idea de que toda representación de la realidad implica una visión, es decir, una codificación de acontecimientos a partir de motivos, tácticas y prefiguraciones. Si precríticamente se concibió a la historia como una «representación de conjuntos de acontecimientos que supuestamente ocurrieron en tiempos pasados» ${ }^{1}$, Hayden White, el importantísimo intérprete de la concepción nietzscheana de la historia, afirma que ésta es en el fondo un acto poético en el que el historiador ha esco-

1. H. White, Metahistoria. La imaginación histórica en la Europa del siglo XIX, trad. de S. Mastrangelo, México: FCE, 1992, p. 9. 
gido tácticas conceptuales para explicar o representar sus datos. Se ha llegado a establecer, como lo hizo una amplia vertiente del siglo xIX, sobre todo en Alemania y específicamente con Leopold Ranke, que la historia puede ser considerada una ciencia rigurosa, cancelando para la mente reflexiva el componente artístico y dramatúrgico que hace de ella un relato, con todo lo que éste implica de posibilidad: un mismo hecho puede ser sometido a diversos métodos interpretativos, a variadas formas de conciencia histórica, y ocupar un lugar distinto, pero igualmente válido, en cada narración. Si postulamos que el pensamiento está cautivo del modo lingüístico en que trata de captar los objetos de su percepción, aquello que justifica como epistemológicamente más valioso un relato sobre otro se evapora, pues, como dice Foucault, «la verdad de las cosas es inseparable del discurso, el mismo que la oscurece y la pierde» ${ }^{2}$. Sea lo que sea la historia -literatura, ciencia rigurosa o auténtico arte- toda reconstrucción histórica tiene algo de ficticio y sus modos posibles algo de formalizaciones de intuiciones poéticas. Así lo muestra El nacimiento de la tragedia, obra en la que se patentiza que si bien el campo histórico es susceptible de presentarse dentro del discurso como un «hecho», en realidad está sometido a anticipaciones de sentido, por lo que no es un campo neutral sino una pantalla sobre la que se proyectan las teorías específicas que conforman una narración literaria de la realidad que se apoya en un círculo hermenéutico en el que prevalecen sólo distintas aproximaciones a la objetividad. Es con aquella obra y con la aparición de Sobre la utilidad y el perjuicio de la historia para la vida con las que Nietzsche se convierte en un parangón de la problematización de la historia al plantear tácitamente a lo largo de su propia narración de la Antigüedad griega serias dudas sobre el valor de «la conciencia histórica", insistiendo en el carácter ficticio de sus reconstrucciones y de la relación «natural» entre «historia» y «realismo». La interpretación nietzscheana de la Antigüedad representa en el marco de la filología clásica una concepción alternativa que utiliza a su modo el aparato conceptual sobre los mismos datos, poniendo a prueba la base teórica desde la cual afirmar legítima y objetivamente la autoridad de cualquiera de los modos de interpretar los hechos. Más aún, nos lleva a cuestionar como parte de su proyecto de genealogía y transvaloración en qué medida podemos hablar de la historia como una ciencia, radicalizando la larga disputa sobre si las explicaciones de las ciencias naturales y las de la historia deben tener las mismas características formales y si no es más bien posible que la historia esté más en relación con el arte que con la ciencia. Al manifestar que todo significado y todo contenido - en la ciencia, en la religión, en cualquier impulso interpretativo - son originalmente estéticos, productos de la necesidad de imponer orden a la experiencia en ausencia de cualquier significado o contenido substantivo, Nietzsche reafirmó con su opera prima, la segunda Intempestiva y Sobre verdad y mentira en sentido extramoral, su posición ultracrítica respecto al encasillamiento del pasado por parte de la ciencia histórica y la consecuente aniquilación de lo que llamó «el espíritu de la Antigüedad».

Situémonos científicamente con respecto a la Antigüedad, podemos entonces tratar de comprender lo pasado con ojos de historiador, o rubricar las formas lingüís-

2. M. Foucault, Nietzsche, la genealogía, la historia, trad. de J. Vázquez Pérez, Valencia: PreTextos, 1997, p. 20. Las cursivas son mías. 
ticas de las obras maestras de la Antigüedad, compararlas y, a lo sumo, restituirlas a unas leyes morfológicas, al modo del naturalista: perdemos siempre lo admirablemente conformador, y la fragancia genuina de la atmósfera antigua $[\ldots]^{3}$.

En su visión de la historia, el filósofo alemán nos invita a contentarnos en su interpretación de la Grecia antigua con la metáfora, con la aproximación, dado que la cosa en sí, el hecho en estado bruto, ni es alcanzable para nadie ni deseable para el creador, papel que asignó al «verdadero historiador»; con ello, comprometió la relación de la historia con la ciencia positivista y la necesidad - monoteísta y cristiana- de creer en una verdad única, poniendo en marcha un juego trágico que reconoce la ilusión como parte fundamental de lo real para deshacerse de una tradición interpretativa cuya institucionalización cerraba el paso al uso de la historia al servicio de la vida, es decir, como escalpelo de crítica cultural y ejercicio de valoración de la propia existencia. En Nietzsche salta a la vista que la concepción de lo que es una obra histórica, de la tarea del historiador, del acercamiento «correcto» al pasado, depende del propio presente, del momento ético en que es concebida, y esto se debe justamente a que la historia no es una ciencia en el sentido más ortodoxo o purista del término. Desde esta visión, el pasado está sometido al juego de la memoria, a un reiterado esfuerzo de reinterpretación que le da sentido a la historia y sustancia al propio presente. Esto significa que si la constante reinvención del mundo antiguo no depende de una pura concepción subjetiva, ya que el hecho no se disuelve en la interpretación, sí está estrechamente relacionada con la creación y necesita de la interpretación selectiva para determinar cuáles son los hechos relevantes y significativos. De este modo, aunque El nacimiento de la tragedia y los escritos filológicos nietzscheanos no pueden analizarse como un caso aislado sino como una dramaturgia sujeta al punto de vista de su propio tiempo, son claro ejemplo de un acto creativo individual en el que el autor trama y argumenta un relato del pasado clásico a partir de una postura y estilo propios con los que, al liberarse del concepto científico de verdad y de la fe en una Razón absoluta, se sitúa en el centro del reconocimiento de la historicidad de toda comprensión, de la condicionalidad histórica y existencial de nuestros conocimientos, los cuales no alcanzan una objetividad final.

Con su segunda Intempestiva, base importantísima para interpretar su obra sobre la tragedia griega, Nietzsche propone transformar la historia de un sueño científico en un sueño creador, que no ofrece un punto de vista superior y que se despliega siempre de forma relativa, sin intentar congelar en la objetividad la función que el pasado clásico puede tener para el propio presente y, más aún, para la propia vida. De este modo, construyó una nueva perspectiva sobre el pasado clásico, pero no para enaltecerla como visión pura sino como apertura a la creación de nuevas posibilidades: «regresar al Partenón», «reinventar la Acrópolis»... pero para liberarse de ellas con un ánimo nuevo y con el impulso de crear una nueva historia para Occidente, restaurando la mentalidad trágica griega en la filosofía como una práctica que reestructura la existencia del hombre a partir de la liberación del cosmos de un sentido último. La tarea de la filología como interpretación del pasado fue para Nietzsche, pues, mucho más amplia que la de

3. Homero y la filología clásica, trad. de L. Jiménez Moreno, Madrid: Ediciones Clásicas, p. 54. 
encontrar un texto original. En él, comenta Manuel Crespillo, el estudio de la Antigüedad tiene más que ver con la vivencia de un Ideal, con una «filología del espíritu» que rechaza las normas de la "filología de etiqueta» ${ }^{4}$. No se trata aquí de la filología como un conjunto de aplicación de técnicas y de una puesta en escena de un reglaje metodológico, sino de «una filología capacitada para practicar un pensamiento límite en el que se instale cómodamente toda una pluralidad simbólica y toda una variabilidad permanente, una filología receptiva ante el caos de una imaginación creadora a la que se reserva una ubicuidad en el complejo aparato de su metodología» ${ }^{5}$. Es así como, poniendo más atención a los significados que a las coordenadas de los hechos, Nietzsche rediseña una Grecia que se opone a la Grecia revelada, a los dogmas académicos y al ejercicio científico que contrarrestan el carácter episódico y metamórfico de la Antigüedad, anteponiendo la «seriedad del realismo» y las normas de su institucionalización. Si partimos de la idea antes propuesta de que la historia siempre enuncia verdades nuevas, me parece que Nietzsche reescribe el pasado a partir de la invención de una historia abscondita cuya intención básica no es la reconstrucción de "cómo realmente sucedieron los hechos» sino un acercamiento estético - no racionalista e intuitivo- que promueve una nueva forma de estar en el mundo en la que los griegos son una metáfora que apunta al ejercicio de una vivencia en tanto que fuerza liberadora y transformadora; se trata, dirá Nietzsche, de «la superación de esa sima entre la Antigüedad ideal —que es tal vez la flor más hermosa de la añoranza germánica del sur- y la real» ${ }^{6}$, de dar a la imaginación creadora un papel prominente en la emergencia de nuevos valores filológicos que ayuden a superar la incapacidad de tocar la vida en sus problemas más desgarradores y enmarcarse en una Weltanschauung en la que lo individual y particular, es decir, los problemas fragmentarios de la interpretación y crítica de textos, queden subsumidos en el todo y la unidad. Este proyecto, aunque larvario, aparecerá ya con toda su fuerza en Homero y la filología clásica y tomará una forma más madura, aunque aún rebosante de entusiasmo, en El nacimiento de la tragedia, donde el acercamiento a este fenómeno cultural no tendrá como objetivo el análisis histórico sino la exposición de una determinada comprensión del cosmos y del hombre que será una puerta abierta hacia lo que, a mi modo de ver, la filosofía de Nietzsche tiene de liberadora: su expresión y contenidos trágicos. Así, la búsqueda de una «nueva Antigüedad» supondrá el arte de decir sí a la vida, de asumir el sufrimiento de manera dionisíaca, como parte de la vida misma, y no cristianamente, como castigo y filtro hacia la consecución de una meta final que habrá de liberarnos del dolor; es en este sentido que Karl Löwith habla de «la repetición anticristiana de la Antigüedad en la cumbre de la Modernidad» ${ }^{7}$, aludiendo al antes y después del cristianismo, a la recuperación del cosmos pagano y al ejercicio de una visión "crítica» que desarma el entramado de suposiciones

4. Cf. M. Crespillo, La mirada griega (Exégesis sobre la idea de extravío trágico), Málaga: Hybris, 1994.

5. M. Crespillo, «La miseria de la filología»: Analecta malacitana. Revista de la sección de filología de la Facultad de Filosofía y Letras 17/2 (1999), 271-290.

6. Homero y la filología clásica, cit., p. 54.

7. Cf. K. Löwith, Nietzsche's Philosophy of the Eternal Recurrence of the Same, Lomax: London University Press, 1987. 
sobre el que se sostienen la visión cristiana del mundo y sus formas de poder, pero que también es una gota de ácido sobre la propia contemporaneidad.

\section{LA SUPERACIÓN DEL HISTORICISMO COMO EJERCICIO TEOLÓGICO}

El horizonte dentro del cual nuestro pensador reconstruye la Antigüedad clásica es un horizonte netamente filosófico que repudia el encajonamiento de la vida en un "proceso» del mundo y el riesgo de quedar cautivo en un esquema de salvación — como la visión judeocristiana teleológica de la historia- o de racionalización - a la que conduce el exceso de historicismo que el propio novel filólogo relacionó con la filología clásica-. En su ejercicio genealógico, Nietzsche descubre los fundamentos metafísicos de la historia, la relación entre certeza, objetividad y verdad revelada, entre los designios de la Providencia y la obediencia a la tradición. Desde esta perspectiva podemos afirmar que en Nietzsche historicismo y teología de la historia se entrelazan de tal modo que ciencia histórica e historia de la salvación son cómplices una de otra en contra del instinto constructor de nuevas posibilidades y senderos distintos, enlazando positivismo, moral y cristianismo. Las consecuencias, desde el punto de vista de la historia al servicio de la vida, son radicales: objetividad a ultranza y ciega tradición cierran toda posibilidad de que el individuo —el historiador, el filólogo, el filósofo- pueda apropiarse del pasado para darse forma a sí mismo y asumir su propia responsabilidad ante el presente y el futuro, la cual sería, fundamentalmente, la función vital de la historia.

Lo que se puede aprender del cristianismo, esto es, que bajo los efectos de un tratamiento histórico algo se deforma y se convierte en antinatural, convirtiéndose en algo definitivamente histórico mediante un tratamiento justo que lo descompone y, por lo tanto, lo destruye, puede aplicarse a todo lo que aún tiene vida. Lo que vive deja de vivir en cuanto empieza a diseccionarse; sufre los dolores de su enfermedad cuando empieza a convertirse en objeto de las prácticas de disección histórica ${ }^{8}$.

Desde la segunda Intempestiva, Nietzsche no dejará de criticar a lo largo de su obra el punto de visita suprahistórico, cuya función es recoger en una totalidad cerrada la diversidad del tiempo con una conciencia escatológica que postula un objetivo final de la historia que trasciende de los acontecimientos en sí. Preguntándose por las cosas primeras y últimas, rebasando en su objeto la simple naturaleza material, historicismo y teología imaginan un principio y un fin que suministra un esquema de orden y significación progresivos: progreso en la investigación para uno, progreso en la historia para la otra, "progreso científico» como secularización de la «esencia escatológica del devenir», del camino redentor de la historia hacia una meta en la que el sufrimiento encontrará su fin en la eterna bienaventuranza. A través de sus escritos podemos apreciar cómo en Nietzsche la crítica a la ciencia se proyecta hacia la crítica de los fundamentos judeocristianos de Occidente, hasta el punto de ver en el sueño objetivista de la «forma verdadera de ver el pasado» un vestigio de la necesidad cristiana de creer

8. UPH, trad. de G. Cano, Madrid: Biblioteca Nueva, 1999, p. 98. 
en el dios único y verdadero. Para nuestro filósofo la ciencia positivista es un equivalente secular de la visión monoteísta del mundo, sostenida en una concepción restrictiva de la verdad que no por ello deja de ser una pura perspectiva entre muchas, una brújula escatológica que es vana ilusión. Tanto la visión tradicional de la filología clásica, expresión sintomática de la enfermedad historicista, y el cristianismo comparten para Nietzsche una memoria obstinada con la que los hombres se atan a sí mismos tanto a un futuro específico como a un pasado fijo. Este atarse al ideal de la objetividad y a la verdad revelada es lo que nuestro filósofo entiende por conciencia moral; como tal, la conciencia histórica institucionalizada defiende a ultranza su propia verdad y, siendo no más que una perspectiva, nos hace caer en los últimos extremos de la posibilidad lingüística: en una automutilación de la propia experiencia vital. Esto significa que la búsqueda de la verdad última de la historia nos prohíbe aceptar como propios los actos del pasado, obstaculizando el olvido creador de lo externo que nos lleva a recordar la propia voluntad y a tomar de la historia aquello que nos construye y nos reafirma. La objetividad y la verdad como dogmas imponen obligaciones respecto al pasado y al futuro, desplazando las perspectivas y exterminando aquello a lo que Nietzsche llamara «el mito»: la capacidad para nombrar las cosas y apropiarse de ellas. Cuando Nietzsche recomienda para acercarse al pasado dejar atrás el fuerte compromiso de ser un epígono de los tiempos y de rendir obediencia ciega al rigor del método y la objetividad científica, nos invita a hacer una labor de limpieza de esa mala conciencia en la que la culpa, el «estar endeudado», exige una compensación para aquellos que han ejercido sobre nosotros su poder ${ }^{9}$. En este sentido, me parece que el nuevo tipo de filología que Nietzsche propone tiene como fundamento el negar al otro el derecho de prescribirnos aquello que debemos pensar y, en relación con el uso del pasado, desarrollar la capacidad para ser un dramaturgo de la historia, reescribiéndose uno a sí mismo como ente activo y dejando atrás aquellas interpretaciones canónicas que fracturan la propia voluntad, recordando, esta vez, que toda interpretación es una forma de poder. Años después de la aparición de su segunda Intempestiva, Nietzsche escribió en La genealogía de la moral:

No hay conjunto de máximas más importante para el historiador que éste: que las causas reales del origen de una cosa y sus usos eventuales, el modo de su incorporación a un sistema de propósitos, son cosas muy distintas; que todo lo que existe, cualquiera que sea su origen, es reinterpretado periódicamente por quienes están en el poder en términos de nuevas intenciones; que todos los procesos del mundo orgánico son procesos de despojo y derrota, y que, a su vez, todo despojo y toda derrota significan reinterpretación, reordenación, en el curso de las cuales necesariamente el significado y el propósito anteriores resultan oscurecidos o se pierden ${ }^{10}$.

9. H. White, op. cit., p. 343: «La mala conciencia no es otra cosa que la incapacidad de aceptar como propios los actos pasados, el impulso a verlos como productos de algún agente o alguna agencia distintos de la propia voluntad, a verlos como manifestaciones de alguna 'cualidad' por encima del propio ser o superior a él. La buena conciencia, en cambio, no es más que el poder de decir que todo lo que ha sucedido o sucederá en el futuro, ha sucedido o sucederá por mi causa, como manifestación de mis propias cualidades».

10. GM, trad. de A. Sánchez Pascual, México: Alianza, 1986, p. 87. 
¿No es hora ya, se pregunta Nietzsche, de entrar en batalla con «un ejército entero de malicia satírica contra las aberraciones del sentido histórico, contra ese deleite excesivo en el proceso en detrimento de la existencia y de la vida, contra el desplazamiento de todas las perspectivas» ${ }^{11}$ ? La interpretación nietzscheana de Grecia plegará un sistema de interpretación a un nuevo sistema y a una nueva voluntad, construyendo otro juego de la historia, esta vez con conciencia de la vaciedad de sus reglas y su posible significación sólo a partir de relaciones de dominación. En este juego, Nietzsche se ha apoderado de las reglas y las ha vuelto en contra de quienes las habían impuesto ${ }^{12}$, y ello porque es consciente de que el significado de estas mismas depende de las intenciones de quienes controlan, en ese momento, los instrumentos de percepción académica y pública. Como señala en La genealogía de la moral, «la historia de una 'cosa', de un órgano, de un uso, puede ser así una ininterrumpida cadena indicativa de interpretaciones y reajustes siempre nuevos» ${ }^{13}$. Este perspectivismo, en el cual ubico la reinvención que Nietzsche hace de Grecia y del propio clasicismo, impide una significación cultural única de la Antigüedad en la misma medida en que rechaza la idea lineal, progresiva y teleológica de la historia a partir de la cual, por otra parte, es posible hablar de identidad y continuidad histórica entre el pasado clásico y la modernidad. A través de su particular clasicismo, Nietzsche reintroduce para el pensamiento el devenir y la intramundanidad como factores existenciales en los que los acontecimientos carecen de un significado que los supere a ellos mismos, buscando despertar a la conciencia histórica a la conciencia de su propia finitud y suavizar el sometimiento de los hechos a perspectivas evanescentes: para que la historia pueda convertirse en una obra de arte, que es precisamente la tarea que Nietzsche le impone, necesita renunciar a toda clase de teologías y sustancialismos en tanto que éstos se oponen a los instintos constructores, cuya obra nunca es suficientemente fija. La historia, como piensa Foucault al interpretar al filósofo alemán, sólo es efectiva cuando introduce en nosotros mismos su propia discontinuidad, cuando dramatiza los instintos interpretativos, oponiéndose a la historia tradicional y socavando aquello sobre lo que se le hace reposar: la muda obstinación por un fin milenario. De este modo, la nueva conciencia histórica que Nietzsche propuso tenía como propósito ser un punto de inflexión y reorientación de las ideas históricas, un intento de desmantelamiento de los criterios de selección y los valores con los que se ha accedido al pasado: la razón funcional, formal e instrumental que defiende el «conocimiento absoluto», la «inteligencia absoluta», el «conocedor puro y sin voluntad», conceptos que «presuponen un ojo como ningún ser vivo es capaz de imaginar, un ojo que no necesita tener dirección, que debe renunciar a sus poderes activos e interpretativos, precisamente los únicos que convierten el ver en ver algo» ${ }^{14}$. El ejercicio científico de la historia se transforma en el pensamiento de Nietzsche en un filosofar

11. UPH 123.

12. M. Foucault, op. cit., p. 41: «El gran juego de la historia es para quien se apodere de ellas, ocupe el puesto de los que las utilizan, se disfrace para pervertirlas, utilizarlas al revés y volverlas contra los que las habían impuesto; para quien, introduciéndose en el complejo aparato lo haga funcionar de tal forma que los dominadores se encuentren dominados por sus propias reglas».

13. GM 88 .

14. GM, citado por H. White, op. cit., p. 351. 
tras del cual se impone el impulso estético de dar forma al mundo de variadas maneras y en distintas versiones, pues «cuantas más emociones dejemos hablar en determinado asunto, más espectáculos diferentes podemos organizar a fin de ver un espectáculo determinado, más completa será nuestra percepción de él, y mayor nuestra objetividad $»^{15}$.

\section{EL REDESCUBRIMIENTO DE LA HISTORIA COMO CONCIENCIA TRÁGICA}

Frente a una historia anticuaria que reduce el repertorio conceptual de la Antigüedad al observarla desde un ideal de objetividad, la recuperación nietzscheana de la sabiduría antigua problematiza el pasado en la medida en que el filósofo alemán retoma para su propio pensamiento la consideración heraclítea del mundo. Al acercarse al pasado clásico desde la perspectiva de la historia al servicio de la vida, Nietzsche hace un redescubrimiento no sólo artístico, literario o cultural, sino existencial, replanteando con ello su herencia para Occidente, sometida ahora a un proceso de interpretación que posterga la validez objetiva y universal del conocimiento empírico y el método analítico, al tiempo que defiende la subjetividad del intérprete, la misma que es reconocida como absolutamente temporal y pasajera. Partiendo de una consideración del tiempo como el topos de lo nuevo y lo que está en constante cambio, para Nietzsche el historiador filósofo ideal sabe que todo lo que vive reclama su decadencia, desde los más pequeños organismos hasta las concepciones más elaboradas del pensamiento, y no se siente azotado por el látigo de la injusticia pues sabe lo siguiente:

Es únicamente la vida quien aquí se expresa, ese poder oscuro e incitante, ese poder que con insaciable afán se desea a sí mismo. Su sentencia es siempre implacable, siempre injusta, porque nunca ha fluido de ninguna fuente pura del conocimiento; pero, en la mayor parte de los casos, resultaría la sentencia igual aunque la pronunciara la misma justicia, porque, «todo lo que nace merece perecer, por eso sería mejor que nada naciese ${ }^{16}$.

El clima intelectual y político del siglo XIX cooperó para que Nietzsche hiciera un énfasis tan radical en el descubrimiento existencial de la Grecia trágica como reconocimiento de la condición absolutamente precaria del ser humano y el juego del mundo, que no conoce más que «esas manos férreas de la necesidad, que agitan el cubilite del azar» ${ }^{17}$, donde la historia se muestra como un transcurrir sin providencia ni causa final, despojando con ello al propio presente de una intensión profunda. Como señala Barrios Casares, la crítica cultural que surge de la interpretación del pasado clásico en Nietzsche supone «la activación del potencial crítico del discurso moderno sobre sus propios presupuestos no cuestionados ni reconocidos como tales» ${ }^{18}$; esto significa que cuando el filósofo plantea en su se-

15. Ibid.

16. UPH 65.

17. A $\$ 130$, trad. de G. Dieterich, Barcelona: Alba, 2002, p. 130.

18. M. Barrios Casares, Voluntad de lo trágico. El concepto nietzscheano de voluntad a partir de El nacimiento de la tragedia, Madrid: Biblioteca Nueva, 2002, p. 20 
gunda Intempestiva que la historia debe resolver el problema de la historia, expresa la imposibilidad de seguir apelando a declaraciones universalistas de principios, sobre todo frente a la experiencia de desfundamentación generada por la propia dinámica de la Modernidad, autocomplacida en los dogmatismos de la vieja concepción metafísica del mundo. En este sentido, la visión nietzscheana de lo que debe ser la historia es heredera de un criticismo ilustrado en el que la razón se autoejercita en la desenmascaramiento y en el que Grecia se hace intempestiva en un sentido proporcional al ejercicio del saber histórico como conciencia trágica: reconocimiento de la precariedad y finitud de toda interpretación del mundo, esfuerzo por soltar las ataduras del propio tiempo, renuncia a ser mero epígono de épocas pasadas y, en su caso, esclavo de las reglas filológicas como obligación generacional. La historia no puede reducirse al rigor del método, a la lógica de un «frío demonio del conocimiento». Se trata, en todo caso, de abrir preguntas y asombrarse de un mundo cuya permanencia está dada por el cambio y llevar estas ideas a una nueva concepción de la historia, la cual Nietzsche fundamentará en la de la concepción del mundo antiguo ${ }^{19}$. La concepción antigua de la historia que Nietzsche reinventa funciona como parámetro para su patología de la Modernidad, disuelve los sentidos absolutos, los fines generalizados, las metas teleológicas, en un intento por deshacerse de la verdad revelada y de la deuda contraída no sólo con el dios monoteísta, sino con el gremio filológico y con la Antigüedad anquilosada del sueño clasicista. Para ello, Nietzsche necesitó confiar en una caracterización del clasicismo que se oponía a la arraigada tradición que hacía de los griegos el pueblo histórico por excelencia, el inventor de la historia, elevando a Heródoto y Tucídides como emblemas del recuento y reflexión sobre los eventos del pasado. En un acto de apropiación, el filósofo alemán postula al pueblo griego como esencialmente ahistórico, como poseedor de una memoria que apunta más al memento vivere, de la cual Tucídides es un «tipo» representativo: el de aquel que hace de su obra algo útil para el presente y que capacita al lector para entender la naturaleza humana, subrayando con ello la necesidad de la historia para la vida y la acción. La ahistoricidad griega significó para Nietzsche el tener control sobre uno mismo así como huir del ideal cristiano; es en este sentido que en el apartado «Lo que yo debo a los antiguos» de Crepúsculo de los ídolos, presenta a Tucídides como un contrapeso de la concepción platónica del mundo.

19. La caracterización de Karl Löwith que podemos usar para entender lo que Nietzsche propone es la siguiente: «Los antiguos fueron más moderados en sus especulaciones. No pretendieron dar un sentido al mundo, ni tampoco descubrir su fin último. Se impresionaron con el orden y la belleza evidentes del mundo, y la ley cósmica de crecimiento y decadencia fue también norma para su comprensión de la Historia. De acuerdo con la interpretación griega del mundo y de la vida, todo se mueve en repeticiones, como las eternas de la salida y puesta del sol, de verano e invierno, de generación y muerte. Consideraron los griegos esta concepción satisfactoria por constituir una explicación natural y razonable del universo, reconociendo que los cambios temporales se producen regularmente, con una constancia de inmutabilidad periódica. Lo inmutable, visible en el orden fijo de los cuerpos celestes, tuvo un interés y valor para ellos que cualquier cambio, por radical y progresivo que fuere. En este mundo intelectual, dominado por la racionalidad del cosmos no había lugar para la significación universal de un único e incompatible acontecimiento histórico. En cuanto al destino del hombre en la Historia, los griegos creyeron que este dispone de sobrados recursos para afrontar con elevación de ánimo y serenidad de juicio cualquier situación, pero de ahí no pasaron. Les interesaba primordialmente el logos del cosmos, no el Dios supremo, ni tampoco el significado de la Historia» (El sentido de la historia, Madrid: Aguilar, 1968, p. 10). 
Mi recreación, mi predilección, mi cura de todo platonismo ha sido en todo tiempo Tucídides. Tucídides y, acaso, el Príncipe de Maquiavelo son los más afines a mí por su voluntad incondicional de no dejarse embaucar en nada y de ver la razón en la realidad, - no en la «razón», y aún menos en la «moral»... Del deplorable embellecimiento de los griegos con los colores del ideal, que es el premio que el joven «de formación clásica» obtiene de su adiestramiento en la enseñanza media para la vida, ninguna otra cosa cura más radicalmente que Tucídides. Es preciso examinar con detalle cada una de sus líneas y descifrar sus pensamientos ocultos con igual claridad que sus palabras: hay pocos pensadores tan ricos de pensamientos ocultos. [...] Tucídides, como la gran suma, la última revelación de aquella objetividad fuerte, rigurosa, dura, que el heleno tenía en su instinto. El coraje frente a la realidad es lo que en última instancia diferencia a naturalezas tales como Tucídides y Platón: Platón es un cobarde frente a la realidad, por consiguiente, huye al ideal; Tucídides tiene dominio de sí, por consiguiente, tiene también dominio de las $\operatorname{cosas}^{20}$.

En contra de todo idealismo, la transvaloración de la historia que Nietzsche propone formula pues un pensamiento trágico en el que el llamado a una nueva consciencia histórica, al servicio de la vida y no de la ciencia, y mucho menos de la verdad de corte teológico, permite arrojar la carga de sustancialismo inoculada al pensamiento para abrir paso a una nueva psicología que incluya a la voluntad, la razón y los sentidos, partiendo de la convicción de que el hombre es ante todo un animal creador de imágenes cuyo fin es individual y subjetivo, dado en el mundo y no fuera de él. Esto me lleva a pensar que la historiografía trágica, presente en El nacimiento de la tragedia, de alguna manera implica ya la disolución de Dios como un acto de la propia imaginación y por ello postula germinalmente la muerte del dios monoteísta que más adelante aparecerá con gran fuerza en la filosofía de Friedrich Nietzsche. Esta disolución parte de lo que Hayden White llama un pensamiento histórico-metafórico que permite la liberación de los esfuerzos por hallar en la historia algún significado definitivo y que ve en el campo histórico «una ocasión para la creación de imágenes, no como materia para la conceptualización» ${ }^{21}$. Así, la evocación actualizada que hace Nietzsche de la helenidad en tanto que filósofo de la historia apunta, según Peter Sloterdijk, no a la visión de un científico sino a la de un mitólogo de la historia como parte de sus exigencias filosóficas. Es posible apreciar en la trabazón dramática de El nacimiento de la tragedia una concepción del transcurrir de la historia en un círculo mítico que va de una profundidad inicial, la de la conciencia trágica de la Grecia arcaica, a una pérdida de ésta a favor de la concepción vulgar y optimista del mundo, la ilustración socrática. Su construcción histórica condensa dos mil quinientos años de historia en un movimiento circular en el que se suceden continuamente el nacimiento y la muerte de un pesimismo heroico, poniendo con ello bajo la lupa, con la esperanza de dejarla atrás, la vulgar concepción del mundo propia de la ilustración socrática, denunciada como insostenible; esto habría de conducir, tarde o temprano, al renacimiento del pesimismo heroico. Sin embargo, si para Nietzsche la historia es circular y, por 
tanto, la historia europea acontece como «el flujo y reflujo de un único motivo, que gira y oscila entre el ascenso, el declive y el regreso ${ }^{22}$; su relato del mundo antiguo griego no debe ser tomado canónicamente: su repertorio es exacerbado y muchas veces contradictorio precisamente por el hecho de que Nietzsche hace una defensa de la historia en su modo metafórico produciéndola, por lo que su transmisión siempre está inmersa en un proceso de recepción en el que, pese a la constancia icónica -Apolo-Dioniso, por ejemplo-, sus elementos permanecen transformables. Si, como reitera James I. Porter, El nacimiento de la tragedia es un proyecto mitológico ${ }^{23}$ que no sólo propone una visión perspectivística —alternativa- de Grecia sino que la dramatiza, en la medida en que promueve una idea del mito como conductor de la sabiduría dionisíaca, crea una disonancia en su propio proyecto, reforzando su aspecto ilusorio: estamos leyendo una serie de mitos que son tomados por historia pero que en el fondo tocan un trasfondo de deseos, de repulsas, de voluntades de poder que revelan su carácter evanescente bajo esa fuerza con la que Nietzsche es capaz de sostener sus propias interpretaciones, y que pueden llevar a una lectura incauta a creer en ellos como algo fijo: «Pues es destino de todo mito irse deslizando a rastras poco a poco en la estrechez de una presunta realidad histórica, y ser tratado por un tiempo posterior cualquiera como un hecho ocurrido una vez, con pretensiones históricas» ${ }^{24}$.

Nietzsche aleja a la historia del sueño objetivista de relatar «cómo realmente sucedieron los hechos» para acercarla a una actividad "mítico-artística» que provee diversas narraciones y no se preocupa por lo que efectivamente sucedió sino por aquello que es digno de ser contado, sin interesarse por la cronología absoluta, zurciendo con gruesas puntadas y groseras junturas los acontecimientos, pero dando una imagen universal de la vida. La historia como obra de arte es sincera en tanto que reconoce la precariedad de sus invenciones, pero, dice Nietzsche, «una historiografía semejante sería experimentada, sin embargo, como una contradicción con la tendencia analítica y antiartística de nuestra época, pues se experimentaría como una completa falsificación» ${ }^{25}$. El hombre moderno, continúa, divaga sin un horizonte rodeado de mitos, su cultura está condenada a agotar todas las posibilidades, a devorar otras culturas alargando la mano como lo hacen los hambrientos, «excavando y revolviendo raíces», «en las más remotas antigüedades» ${ }^{26}$ : «El enorme apetito histórico de la insatisfecha cultura moderna, el coleccionar a nuestro alrededor innumerables culturas distintas, el voraz deseo de conocer, ¿̇a qué apunta todo esto si no a la pérdida del mito, a la pérdida de la patria mítica, del seno materno mítico?» ${ }^{27}$.

22. P. Sloterdijk, El pensador en escena. El materialismo de Nietzsche, trad. de G. Cano, Valencia: Pre-Textos, 2000, p. 53: «Lo que transcurre cíclicamente es un pesimismo heroico, que nace y muere como un ser vivo, seguro de su renacimiento. Aquí podemos observar un ritmo arcaico a tres tiempos: el nacimiento de la tragedia del espíritu de la música griega; la muerte de la tragedia a causa del optimista programa liberador de una pretendida ilustración; y el renacimiento de la tragedia griega a partir del espíritu de la música alemana $[\ldots] »$.

23. Cf. J. I. Porter, The Invention of Dionysus: an Essay on The Birth of Tragedy, Stanford: Standford University Press, 2000.

24. NT, trad. A. Sánchez Pascual, Madrid: Alianza, 1994, pp. 98-99.

25. UPH 96-97.

26. AC 180.

27. Ibid. 
$\mathrm{Al}$ asumir la diferencia fundamental entre la concepción cristiana de la historia y la clásica respecto a su actitud frente al pasado y el futuro, Nietzsche se compromete con la visión antigua que suministra una lección moral a partir de una cosmovisión trágica: no infatuarse indebidamente de los propios triunfos, reflexionar sobre la veleidad de la fortuna, ser moderado en los tiempos de prosperidad y aprender de la desgracia. En su profunda crítica al clamor patriótico de su presente, el filósofo conserva en su concepción de la conciencia histórica un «sentimiento clásico» que reflexiona sobre lo ineluctable de todas las cosas humanas, aceptándolo sin tristeza, virilmente, amándolo incluso. Así, el pensador se comporta ante la Alemania de Bismarck como Polibio lo hizo ante la desaparición de la monarquía macedónica, recordando las palabras de Demetrio frente a la conquista del imperio persa por Alejandro:

Y, sin embargo, esta fortuna, que nunca está de acuerdo con la vida, que siempre se burla de nuestros cálculos con algún acontecimiento imprevisto, que demuestra incesantemente su poder al defraudar una y otra vez nuestras esperanzas, ahora también, según a mí me parece, al conceder a los macedonios la riqueza de todos los persas, hace ver claro a todos los hombres que únicamente les hace préstamo de semejante prosperidad hasta que decida obrar de manera diferente ${ }^{28}$.

Como señala Foucault, la historia es el cuerpo mismo del devenir, y por ello también padece de desfallecimientos, de furores, de agitaciones febriles ${ }^{29}$; en este sentido, aunque para Nietzsche el historicismo está lejos de aceptar con una "perspectiva clásica» la inescapable fatalidad del declinar, el mundo moderno no es ni firme ni duradero, como tampoco su concepto de cultura ni su amor a la «verdad». Ahí pone Nietzsche su esperanza, aunque la dificultad radique en olvidar lo que se sabe para fijarse un nuevo fin. La "filosofización» de la historia, $\mathrm{y}$ de hecho, de toda la cultura, tiene que ver con el restablecimiento de una conciencia «clásica» de lo mudable frente a la cual se devela el inevitable componente perspectivístico de todo conocimiento. Si tomamos las distintas imágenes de la historia como resultado de otras tantas interpretaciones, debemos rechazar la implicación moral de los hechos históricos y la sublimación de la realidad concreta en fuerzas espirituales intemporales. De ahí a una historiografía trágica, e incluso irónica, hay sólo un paso, y es que, desde este punto de vista, hablar de la historia nos invita no sólo a pensar en la contrariedad de la construcción del pasado sino, más aún, en las bases ficticias sobre las que se apoya nuestra ilusión de permanencia y autosuficiencia; con esto, el escepticismo frente a toda referencia a un principio y fin últimos como directores del acontecer humano parece inevitable. Como señala Nietzsche, hay dos tipos de historia: la que afirma que hay «un modo verdadero de ver el pasado», y que restringe la vida, y otra para la cual hay tantas «verdades sobre el pasado" como perspectivas individuales sobre él. Esta última afirma la relatividad de toda visión como máxima del modo vital de considerar la historia y reflexiona sobre la creencia en una historia eternamente verdadera como un vestigio más de la necesidad cristiana de creer en el dios único, cuyo remanente también es la ciencia positivista.

28. Polibio, Historias, XXIX, 21, citado por K. Löwith, op. cit., p. 15.

29. Cf. M. Foucault, op. cit., p. 24. Las cursivas son mías. 
La Grecia problemática y problematizadora de Nietzsche es, pues, un instrumento filosófico que quiere liberar a la conciencia de causas superiores para devolverle el disfrute de sus poderes metafóricos, los cuales se muestran como autoconscientes y propician la liberación del hombre para una actividad que se le antoja heroica, irregulable e incalculable. En este sentido, el neohumanismo nietzscheano reclama en su interpretación una revaloración del individuo frente a la tradición como ley y como verdad, después de reconocer una profunda afinidad entre objetividad y debilidad historiográfica. Me atrevo a afirmar que en El nacimiento de la tragedia Nietzsche construyó una idealización "antigua» de la historia en la que, como Tucídides, se da más importancia a lo que pudo haber sido que a lo que fue; o como Plutarco y Polibio, quienes no concebían la historia como algo que tiene un principio y un final, como lo tendría la historia judeocristiana con la creación y la resurrección, sino, a lo sumo, como un repertorio de ejemplos. Es así que, para Hayden White, el repudio del «realismo» en la filosofía de la historia por parte de Nietzsche constituye una defensa metafórica del acercamiento al pasado, en la que la Grecia clásica se transforma en una forma figurativa que señala hacia la actualización de cierta visión del mundo, partiendo de la afirmación de que no hay un sentido dado que espera por su total despliegue en el tiempo ni tampoco una verdad absoluta susceptible de ser abarcada en su totalidad por la razón. Grecia reinventada en la metáfora combate a la razón justificadora, a la ocupación en la historia pasada como ocupación crepuscular, es decir, como paralización frente al hecho consumado y renuncia a la praxis, doblegándose a una autoridad superior que revela el «cómo fue» y el «hacia dónde». En tanto que mitólogo de la historia, Nietzsche se acercó a las figuras clásicas como caracteres más bien que como individuos propiamente históricos, añadiéndoles nombres propios en la medida en que para él pensar históricamente significa pensarse a uno mismo como conciencia aristocrática, libre, fuerte y noble, la cual se da a sí misma el poder de «nombrar» las cosas y tomar posesión simbólica de aquello que se ha nombrado: "Quien interpone entre sí y las cosas conceptos, opiniones, cosas del pasado, libros, quien ha nacido, pues, en el sentido más amplio, para la historia, no verá nunca las cosas por primera vez, ni será él mismo una de estas cosas vistas por primera vez ${ }^{30}$.

Finalmente, resta decir que el helenismo como evento histórico se ha transformado con el pensador alemán en una profunda reflexión que atenta contra el credo racional de la modernidad sobre el cual se sostenía la filosofía de la historia. Con su dramática intervención en una serie de eventos de la historia universal, Nietzsche patentiza la estructura dramática de las filosofías de la historia modernas, pone en entredicho los fundamentos de la objetividad científica del saber histórico, al cual ha ubicado dentro del impulso teológico de encontrar una verdad absoluta, propio del cristianismo. Éste, me parece, es parte del contexto en el que podemos apreciar el alcance del pensamiento de Nietzsche sobre la historia, el cual es interesante, e ineludible en la interpretación de su pensamiento, por varias razones: porque frente a la filosofía de la historia, sin renunciar a la idea de la historicidad del hombre, propone como fundamento

30. SE, trad. de J. Muñoz, Madrid: Biblioteca Nueva, 2000, p. 104. 
una filosofía de la vida. En segundo lugar, porque su crítica al historicismo científico, como modelo de crítica epocal, abre un camino al lugar que debe ocupar la historia en la valoración de la existencia humana. Y, en tercer lugar, porque la manera que tiene Nietzsche de apreciar la historia, a través de sus escritos sobre Grecia y la segunda Intempestiva, constituye un primer y profundo ejercicio práctico en la crítica genealógica de la ciencia histórica y su fidelidad a la obediencia metafísica. 